\title{
The development of real-time communication network based on Zigbee and Ethernet for Photovoltaic systems
}

- Phan Quoc Dung

- Dao Ngoc Dat

- Le Chi Hiep

Power Electronics Research Lab, University of Technology, VNU-HCM

(Manuscript Received on April 28 ${ }^{h}, 2014$; Manuscript Revised August 13 ${ }^{\text {th }}$, 2014)

\begin{abstract}
:
In a large system with a lot of distribution solar sources which are all connected to the national grid, a communication system becomes the important part for data acquisition in order to control the whole system stable and efficiency. To deal with this challenge, this paper presents a solution based on Zigbee and Ethernet communication standard. Zigbee standard was created to be a specification of a high level wireless communication protocol which is not only secure, reliable, simple but also low cost and low power. With Zigbee, we can create a communication network for hundreds to thousands of mini solar sources in a large scale of photovoltaic system. Ethernet is a high speed wired communication technology that is used widely in industrial and automatic
\end{abstract}

applications. Together Zigbee and Ethernet bring to us a real-time communication solution for the system. In the experiment prototype of this paper, we use the CC2530ZNP-Mini Kit to create a simple network includes one coordinate and one end device for the first step. The end device was configured to get current and voltage values from a 3-phase grid-connected solar inverter $800 \mathrm{Wpk}$ and then sends the values to the coordinate. After the coordinate received data, it would send them to an Ethernet controller board. To display the data through Ethernet, we embedded a web server on the Ethernet controller board. By this way, the data was easy to visualize and supervised by using any web browser.

Keywords: Zigbee, Ethernet, Web server, 3-phase grid-connected solar inverter.

\section{INTRODUCTION}

As a result of the increasing integration of renewable energy sources in the power system also the sharp increase in decentralized power generation, the reliable management of power supply systems is increasingly challenging. This development goes hand in hand with the rapid growth in the demand for communications.

There are a lot of communication requirements for new energy applications, such as meter data management, distribution automation, and automatic control. The main objective of this 
paper is to describe the basic design and implementation of a communication system which is realizable, stable, and cost-suitable of a renewable distributed generation system.

Central to the operation of any power system is its control architecture consisting of hardware and software protocols for communication system parameters and control signal. In conventional electric power systems, this is accomplished by Supervisory Control and Data Acquisition (SCADA) systems [1]. There are many companies that provide SCADA solutions such as Siemens, Schneider, ABB, etc. However, in the large scale of distributed renewable generation systems, with a lot of inverter gridconnected devices, lot of sensors, protection devices, the cost-effective solution is integrating the communication feature to the hardware devices instead of using addition devices from the mentioned companies.

There are many communications technologies divided into two main communications media: wired and wireless, can be used for data transmission between sensors and power electronics converters to control center. In some case, wireless communications have some advantages over wired technologies, such as low cost infrastructure and ease of connection to difficult or unreachable areas. However, the data rate of wireless is lower than wired technology. So that, wireless technologies with constrained bandwidth and security and reduced installation costs can be a good choice for large-scale renewable system deployments [2]. On the other hand, wired technologies with increased capacity, reliability and security can be used for a long distance transmission. To provide system reliability, robustness and availability at the same time with appropriate installation costs, a hybrid communication technology mixed with wired and wireless solutions can offer a good solution [3].

In the communications infrastructure, reliable and real-time information becomes the key factor for reliable system operation while generating electricity from renewable sources and injecting to the national grid. The impact of environmental conditions, fault conditions, hardware errors, which cause power disturbances and outages, can be largely avoided by online power system condition monitoring, diagnostics and protection. For that reason, the real-time monitoring and control enabled by high speed communication technologies have become essential to realize the distributed renewable generation system. Furthermore the communication infrastructure should be scalable enough to facilitate the upgrading of the power system. More renewable energy resources, power conversion devices, smart meters, smart sensor nodes and smart data collectors will join the system and each device should to be connected to the communication network [4] [5].

The proposed communication system control and monitor the operation of electric power systems by using Ethernet and Zigbee standard working in collaboration to achieve the mentioned requirement of the system.

\section{OVERVIEW OF A PV SYSTEM WITH THE PROPOSED COMMUNICATION NETWORK}

A photovoltaic (PV) power system is a largescale photovoltaic system consisting photovoltaic panels, power electronics converters, inverters, sensors, measurement collection devices, protection devices. The system designed for the supply of solar energy into the electricity grid. In this system, the grid-connected inverters convert the energy of sunlight, which generated by the PV panels into electricity which is fed directly into the national electricity grid without storage in batteries. A group of PV panels is connected to a grid-connected inverter box. Each PV inverter contains its own microcontroller which controls the operation of the inverter. In fields today a 
large-scale PV system has hundreds of panels, thus to ensure maximum system performance, efficiency and guarantee the safety of people, property, a monitoring system based on a communication infrastructure are being used.

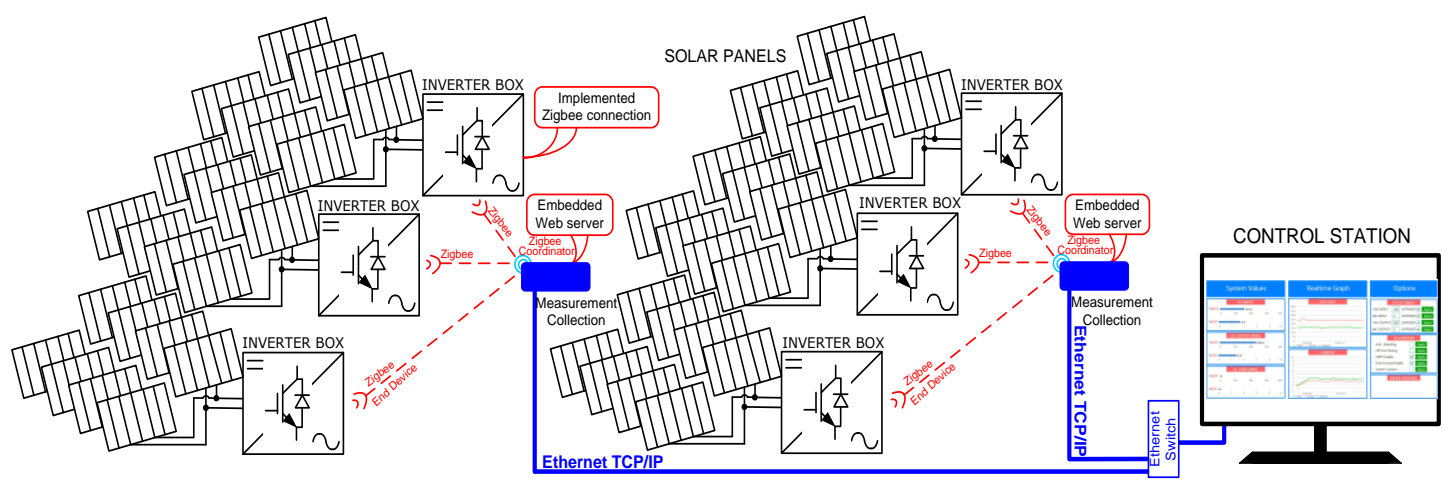

Figure 1. Overview of a PV system with the proposed communication network

The communication must be based on an industrial technology, which offers system engineers a flexible, custom configuration for total control over the PV generation plant. The control system provides simplified, centralized, reliable and secure data management, essential in achieving maximum energy production. Access to real-time and visualize data as well as anomaly alarm notifications enable technicians to provide effective, preventative and corrective maintenance of the renewable energy generating system in a timely manner.

In the proposed communication network, two types of communication infrastructure are needed for information flow in a PV generation system. The first flow is from sensors and power converters to measurement collection devices, the second is between measurement collection devices and the data centers. The first data flow can be accomplished through wireless communications: ZigBee. For the second information flow, Ethernet technology is used. Real-time values of all important electrical parameters can be consulted by the supervisors every time. Current values are represented for each inverter, string or panel PV. In addition to that, a web embedded interface is installed for each measurement collection device to monitor and to control the quality of the electrical source, looking at Total Harmonic Distortion (THD), voltage, current, power, energy, ground isolation and ground leakage current values. The information is available for each inverter, as well as the total energy of the power plant. To facilitate the supervisors in checking the status of the plants, a visual color graph has been designed. These graphs indicate the power produced by the inverters at any time and allows the supervisors to identify any problems in the installation down to string level. This feature of the monitoring system enables supervisors to detect specific strings that are operating at a lower efficiency level than their normal operation. For maintenance purposes, engineers can visit the site and monitor all parameters of the strings or test the strings that indicate lower efficiency levels.

In Fig.1, the major devices of a PV system with the proposed communication network are presented:

(1) The inverter box: Each inverter box has a power electronics inverter inside. By controlling with the advanced algorithm, the power electronics inverter can be able to greatly improve the efficiency of the hold PV system [6].

(2) Sensor: Most of the sensors were integrated 
inside the inverter box for sensing the operation of the power electronics inverter. These sensors will serve as the basis for communications, computing and control. All measurement signals will be transmitted periodically by using Zigbee standard. Zigbee whose advantages include reliability, high accuracy of data transmission, and low maintenance costs.

(3) Communications: One Zigbee end device was implemented inside the inverter box for sending sensor values and the operation parameters of the solar inverter to one Zigbee coordinator which was integrated into the measurement collection device. Each measurement collection device also has its own high-speed Ethernet connection controller, which transmits all measurement data to the control station over Ethernet cable. Furthermore, the measurement collection device can also receive control signals from the control station in the local area network.

(4) Computing and control station: By connecting to the local area network over Ethernet connection, the control station gets data for monitoring and visualization. Web browsers were used for display data. However, monitoring of the data is just the first step, the second is using the information to control the power generation operates reliability, safety with the highest efficiency and furthermore to balance generation with demand.

\section{ETHERNET}

Ethernet is by far the most widely-installed Local Area Network (LAN) technology today in the world, connecting more than 85 percent of the world's LAN connected PCs and workstations. More than 300 million switched Ethernet ports have been installed worldwide. Ethernet has matured across the last four decades into its role as the basis of the IEEE $802.3^{\mathrm{TM}}$ standard, which specifies the physical and lower software layers, and is the foundation of high-speed communications. Ethernet has become a popular networking technology because it is easy to understand, deploy, manage, and maintain. Ethernet is also low cost, high width, flexible and versatile support for multiple applications especially high speed data communication. Furthermore, Ethernet supports a variety of network topologies and can run over both optical fiber, and twisted-pair cables, thus making Ethernet networks are scalable from the simplest to most complex networks or up to 248 network nodes, from a few meters to about $40 \mathrm{~km}$ of distance. Over the years, Ethernet has steadily evolved to provide additional performance and network intelligence. This continual improvement has made Ethernet became a highspeed communications technology for a tremendous range of established and emerging applications, including datacenter networks, personal computers, laptops, tablets, smartphones, power infrastructure and smart meters, etc. [7].

In this embedded applications, Ethernet is used for remote monitor and control of data running at both $10 \mathrm{Mbit} / \mathrm{s}$ and $100 \mathrm{Mbit} / \mathrm{s}$ (and is often referred to as 10/100 Ethernet). The Ethernet control board used in this paper is shown in Fig2. The Ethernet controller was integrated with the host microcontroller STM32F407. The STM32F407 is a product of STMicroelectronics. It is designed for medical, industrial and consumer applications where the high level of integration and performance, embedded memories and rich peripheral set inside packages as small as $10 \times 10 \mathrm{~mm}$ are required. The STM32F407 offers the performance of the Cortex $^{\mathrm{TM}_{-} \mathrm{M} 4}$ core (with floating point unit) running at $168 \mathrm{MHz}$. The Ethernet peripheral enables the STM32F407 to transmit and receive data from the Ethernet cable and manages Ethernet protocol in compliance with the IEEE 802.3-2002 standard.

\section{Trang 8}


The communication over the local area network in this Ethernet embedded system is accomplished by implementing a small TCP/IP (Transmission Control Protocol / Internet Protocol) stack called LwIP (lightweight IP). TCP/IP defines a set of rules to enable computers to communicate over a network, specifying how data should be packaged, addressed, shipped, routed and delivered to the right destination. Nowadays, the TCP/IP protocol has become the widely used and important protocol for most data communication networks. The LwIP is a small independent implementation of the TCP/IP protocol suite that has been initially developed by Adam Dunkels at the Swedish Institute of Computer Science and is now developed and maintained by a worldwide network of developers. It focuses to reduce memory usage and code size while still having a full-scale TCP. It is making LwIP suitable for use in embedded systems with very limited resources.

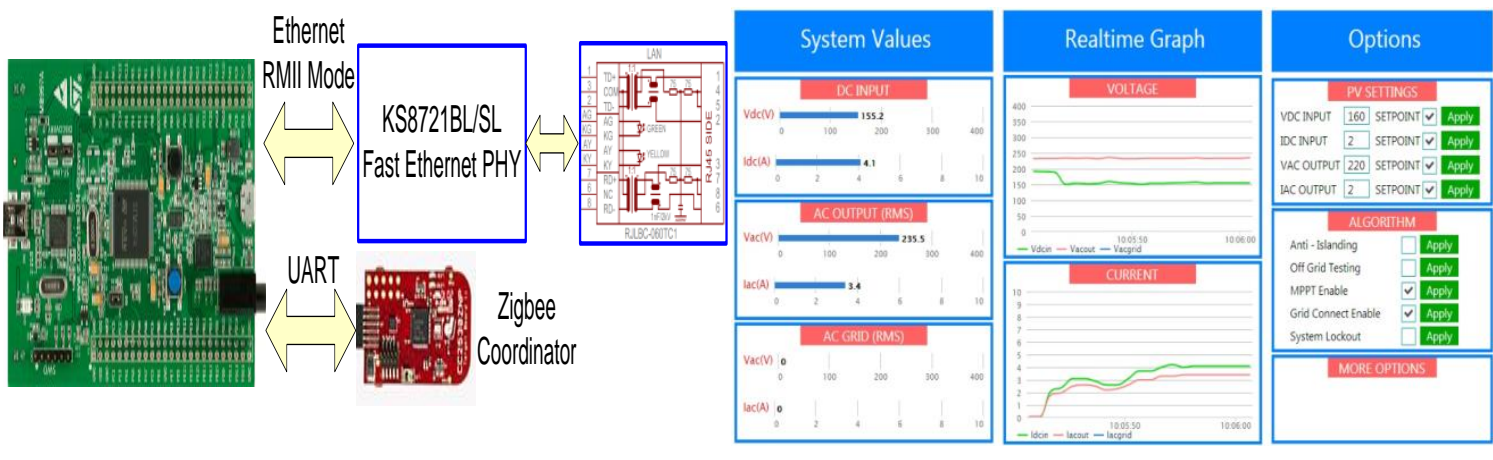

Figure 2. Measurement collection device block diagram

\section{WEB SERVER SERVICES}

By implementing Web services in measurement collection devices, it becomes easy to monitor and manage a lot of devices by using any web browser. The embedded Web server is a real-time data server. It brings simplified access to information, a reduction in the costs of development and deployments, no need for software licenses, plus an increase in productivity. The Web server is fully customizable so that it can be adapted to the system's requirements. All the data can be presented in the form of standard Web pages in HTML (HyperText Markup Language) format and can therefore be accessed using any Web browser that supports the embedded Java code. This service is a convenient way to monitor the status of devices on the network and to access operational and
Figure 3. Web site monitor embedded in STM32F407

configuration information. No programming is required at the PC (personal computer) running the Web browser.

When you try to access a Web page, the Web browser issues a request to the server using the HTTP protocol. The Hypertext Transfer Protocol (HTTP) is designed to enable communications between web browsers and web servers. HTTP works as a request-response protocol between a web browser and web server. In this application, a program wrote for the microcontroller STM32F407 that embedded a web site is the server. Example: A web browser submits an HTTP request to the server. After the server handles the request, it sends the HTML pages back to the web browser.

The web page in Fig.3 was designed by using 
HTML which is the main markup language for creating web pages and other information that can be displayed in a web browser. The Fig.4 shows the list of algorithm options which can apply to the system via the web browser.

\section{ZIGBEE}

ZigBee is a standards-based technology for remote monitoring, control and sensor network applications. ZigBee utilizes IEEE 802.15.4 compliant radios. It has 16 channels in the 2.4 $\mathrm{GHz}$ band, each with $5 \mathrm{MHz}$ of bandwidth. The transmission range is between 1 and $100 \mathrm{~m}$ with a $250 \mathrm{~Kb} / \mathrm{s}$ data rate. The ZigBee standard is the good solution that specifically addresses the typical requirements for wireless control and monitoring applications for a renewable generation system such as: large number of nodes/sensors/devices, very low system/node costs, low-power consumption, reliable and secures links between network nodes, easy deployment and configuration. Furthermore, ZigBee supports self-healing mesh networking, which is a decentralized network topology. It

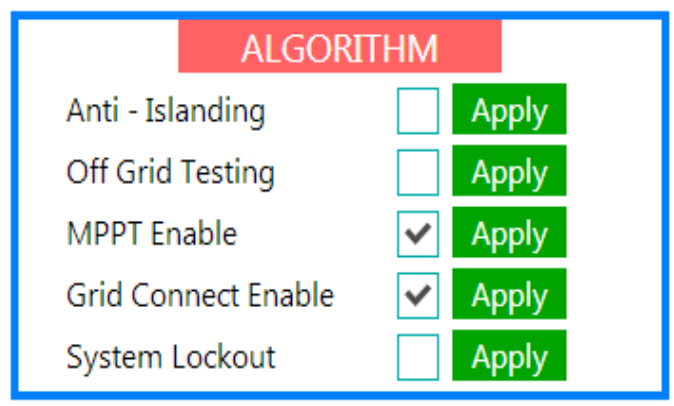

Figure 4. Algorithm options for the solar inverter

An example network is shown in the Fig.5, with the ZigBee coordinator, the routers and the end devices. The Zigbee hardware was used in this application is the CC2530ZNP (ZigBee Network Processor) from Texas Instrument. The CC2530ZNP is a cost-effective, low power, ZigBee Processor that provides full ZigBee functionality with a short development time. The hardware consists of a CC2530 allows nodes to find new routes throughout the network if one route fails, making ZigBee a robust wireless solution [8]-[10].

There are three logical device types in a ZigBee network - (i) Coordinator (ii) Router and (iii) End device. A ZigBee network consists of a Coordinator node and multiple Router and Enddevice nodes.

The coordinator is the device that "starts" a ZigBee network. It is the first device on the network. The coordinator node chooses a channel and a network identifier and then starts the network. The coordinator node can also be used, optionally, to assist in setting up security and application-level bindings in the network. The router functions are allowing other devices to join the network and assisting in communication by delivering the message of the end-device. The end-device has no specific responsibility for maintaining the network infrastructure, so it can sleep and wake up as it chooses. End-devices only wake periodically to send and/or receive data to/from their parent.

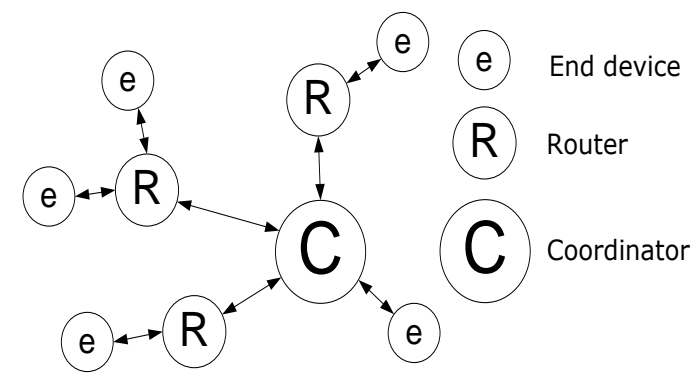

Figure 5. A mesh Zigbee network example

ZigBee device preprogrammed with ZigBee software and an MSP430F2274 microcontroller that controls the ZigBee device. In particular, the CC2530 ZigBee SoC (System on Chip) handles all the ZigBee protocol tasks and thus, leaves the resources of the application microcontroller free to handle the application.

\section{Trang 10}




\section{IMPLEMENTATION}

The experimental prototype contains the devices which are presented in the following:

\subsection{Solar panels and a three-phase grid- connected inverter}

Solar panels are connected in parallel and series in order to provide total $800 \mathrm{~W}$ peak. The output voltage of the array solar panels is connected to the input of the inverter through circuit breakers and fuses for preventing the short circuit conditions. The solar inverter (Fig.6) was controlled by dSPACE digital control technology with efficient power conversion topology to achieve high efficiency solar power conversion. The maximum power point tracking algorithm ensures the solar inverter is extracting a maximum amount of power harvested from solar photovoltaic array regardless of environmental conditions. The output of the inverter is the three-phase AC voltage which is controlled synchronous with the three-phase grid $380 \mathrm{~V}, 50 \mathrm{~Hz}$ in order to inject the three-phase AC current to the grid. One computer was used to control and monitor the operation of the inverter through the dSPACE digital controller.

\subsection{CC2530ZNP End device}

In Fig.7, the CC2530ZNP end device was put at the solar inverter to read values from four sensors: input current, input voltage of the inverter (are also the output current and voltage of the solar panels array) and output current, voltage of one phase of the inverter. This CC2530ZNP was set up to be the end device in order to send values of these sensors to the
CC2530ZNP coordinator over the Zigbee network.

\subsection{The measurement collection device}

This device (shown in Fig.8) was controlled by the microcontroller STM32F407. The web site for monitoring was embedded to this microcontroller. To access the website, we connect an Ethernet cable to this device and then use any web browser with the address 192.168.6.9. The data transmitted and received between the measurement collection device and personal computer was handled by the Ethernet peripheral of STM32F407 through Ethernet connection. One CC2530ZNP was configured to be the Zigbee coordinator in order to receive data from or transmit control signal to Zigbee end devices in the Zigbee network. This Zigbee coordinator communicates with the microcontroller STM32F407 through UART (Universal asynchronous receiver transmitter) connection.

The main functions of the measurement collection device are: (1) The Zigbee coordinator receives data which were transmitted from Zigbee end devices in the Zigbee network, then send data to the microcontroller STM32F407. The STM32F407 transmits data to a web browser using Ethernet interface with LwIP protocol over Ethernet twisted-pair cable; (2) by using a web browser, control signals were sent to the measurement device through Ethernet cable. After receiving control signals, the STM32F407 sent the signals to the CC2530ZNP coordinator in order to forward the signals to CC2530ZNP end devices, thus to control the solar inverter. 


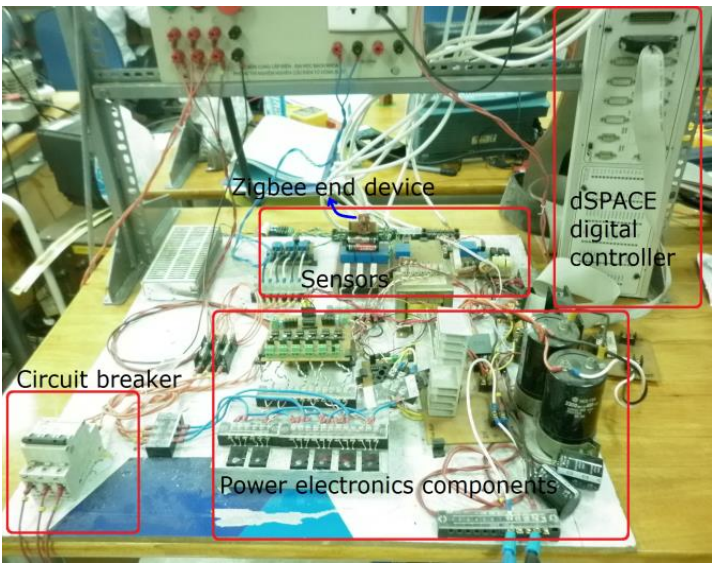

Figure 6. The three-phase grid-connected solar inverter (PERLAB-HCMUT®)

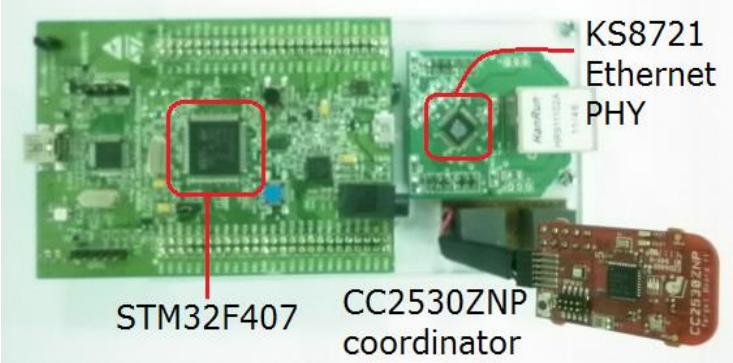

Figure 8. Zigbee coordinator with the measurement collection device

The current input and output of the solar inverter was monitored and visualize by the web browser as shown in Fig.9. The current in Fig.9 increased from $2 \mathrm{~A}$ to $4 \mathrm{~A}$ depend on the sun radiation. By monitoring the current values, supervisors can detect specific solar panels strings with its solar inverter that are operating at a lower power level than their normal operation. The shade conditions affect the performance of many, if not most solar systems which are causing the low power harvested operation of the solar inverter - for example, falling leaves gone with the wind can drop on the solar panels surface or the surface of solar panels can be covered in dust over time. When the reason causing the low power harvested

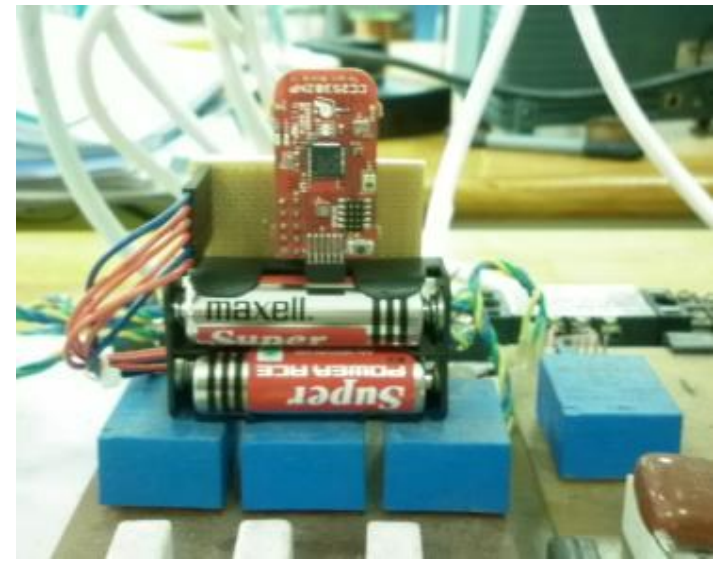

Figure 7. Zigbee end device at the solar inverter

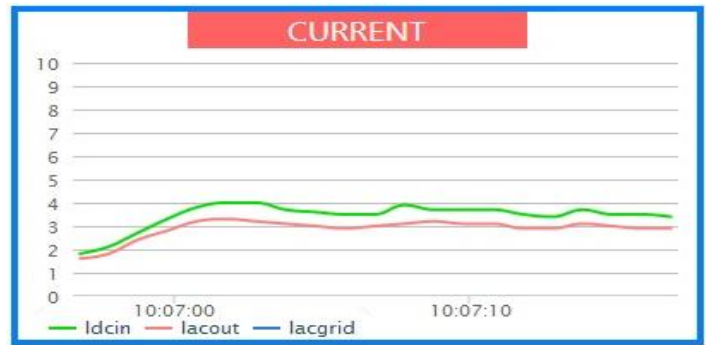

Figure 9. Monitor of current input and output of the solar inverter

solar inverter operation was detected, it can be fixed soon, and thus the solar inverter can get back the normal operation soon.

\section{CONCLUSION}

This paper mentioned the communication network architecture for photovoltaic systems. Wired and wireless connection was used. The Zigbee wireless protocol was used to collect data from the solar inverters, and then send data to the measurement collection device at around $100 \mathrm{~m}$ of distance. Once the data are collected, the data will be delivered to supervisors by using an Ethernet connection with the maximum data rate is $100 \mathrm{Mbit} / \mathrm{s}$ over the twisted-pair cable. ZigBee is a global standard for wirelessly

\section{Trang 12}


networked control and monitoring solutions that are reliable, cost-effective, low-power, especially for a large-scale distributed solar generation system. Ethernet is based on standards (IEEE802.3) that ensure reliability of network connections and data transmission. Ethernet is suitable for high speed data and long distance connection. The measurement collection devices aggregate the performance data from each solar inverter. A web site has been integrated into these devices, thus the data can be visualized by the web browser for performance analysis, fault detection and troubleshooting of PV systems or for controlling each solar inverter by sending control signals. Once the Ethernet network was built, the data can be monitored easily. No need to install any specialized software - All needed is a web connected device address to get access to system data. The simple implementation was set up for verifying the feasibility of the proposed communication network. The solar inverter connected to the three-phase grid to inject the power harvested from sunlight to the gird. One Zigbee end device CC2530ZNP was put at the solar inverter and one measurement collection device was connected to a personal computer to monitor data over Ethernet connection. Based on the results obtained in the web browser, it promises a reliable solution for communication of a large-scale solar system.

ACKNOWLEDGMENT: This research is funded by Vietnam National University - HCM City, HCMC University of Technology under grant number B201220-04TÐ. The authors gratefully acknowledge the Power Electronics Research Lab at University of HCMUT for providing excellent facilities.

\section{Xây dựng mạng truyền thông thời gian thực trên cơ sở Zigbee và Ethernet cho hệ thống pin năng lượng mặt trời}

- Phan Quốc Dũng

- Đào Ngọc Đạt

- Lê Chí Hiệp

Trường Đại học Bách khoa, ĐHQG-HCM

\section{TÓM TÁT:}

Trong một hệ thống lớn với rất nhiều nguồn năng lượng mặt trời được nối với lưới điện quốc gia, truyền thông trở thành một thành phần quan trọng trong việc thu thập dữ liệu để kiểm soát toàn bộ hệ thống ổn định và hiệu quả. Đối với vấn đề này, bài báo trình bày một giải pháp dựa trên tiêu chuẩn truyền thông Zigbee và Ethernet. Tiêu chuẩn ZigBee có đặc điểm kỹ thuật của một giao thức truyền thông không 
dây cao cấp không những an toàn, đáng tin cậy, đơn giản mà còn có chi phí thấp và năng lượng thấp. Với Zigbee, chúng ta có thể tạo ra một mạng lưới thông tin liên lạc cho hàng trăm đến hàng ngàn nguồn năng lượng mặt trời nhỏ trong một quy mô lớn của hệ thống quang điện. Còn Ethernet là một công nghệ truyền thông (có dây) tốc độ cao được sử dụng rộng rãi trong các ứng dụng công nghiệp và tự động. Cùng với nhau, Zigbee và Ethernet mang đến cho chúng ta một giải pháp truyền thông thời gian thực cho hệ thống. Trong mô hình thử nghiệm của bài báo này, chúng tôi sử dụng Kit CC2530ZNP để tạo ra một mạng đơn giản bao gồm một thiết bị phối hợp và một thiết bị đầu cuối cho thử nghiệm bước đầu. Các thiết bị đầu cuối đã được cấu hình để đo đạc giá trị dòng và điện áp từ mô hình bộ biến đổi công suất kết lưới ba pha năng lượng điện mặt trời 800Wpk và sau đó gửi các giá trị đến thiết bị phối hợp. Sau khi thiết bị phối hợp nhận được dũ̃ liệu, nó sẽ gửi dữ liệu đến một bo điều khiển Ethernet. Để hiển thị các dũ liệu thông qua Ethernet, chúng tôi nhúng một webserver trên bo mạch này. Bằng cách này, dữ liệu dễ dàng được hiển thị và giám sát bằng cách sử dụng bất kỳ trình duyệt web nào.

Tù̀ khóa: Zigbee, Ethernet, Web-server, bộ biến đổi công suất kết lưới ba pha.

\section{REFERENCES}

[1]. Yu F.R, Peng Zhang, Weidong Xiao, Choudhury P, "Communication systems for grid integration of renewable energy resources" Network, IEEE (Volume:25, Issue: 5), 2011

[2]. Parikh P.P, Kanabar M.G, Sidhu T.S, "Opportunities and challenges of wireless communication technologies for smart grid applications", Power and Energy Society General Meeting, 2010 IEEE

[3]. Ye Yan, Yi Qian, Sharif H, Tipper D, "A Survey on Smart Grid Communication Infrastructures: Motivations, Requirements and Challenges", Communications Surveys \& Tutorials, IEEE (Volume: 15, Issue: 1), 2013

[4]. Islam S.Z, Mariun N, Hizam H, Othman M.L, "Communication for Distributed Renewable Generations (DRGs): A review on the penetration to Smart Grids (SGs)", Power and Energy (PECon), 2012 IEEE International Conference on
[5]. Gungor V.C, Sahin D, Kocak T, Ergut S, "Smart Grid Technologies: Communication Technologies and Standards", Industrial Informatics, IEEE Transactions on (Volume:7, Issue: 4 ), Nov 2011

[6]. Khalifa A.S, El-Saadany E.F, "Control of three phase grid connected photovoltaic power systems" Harmonics and Quality of Power (ICHQP), $201014^{\text {th }}$.

[7]. Skendzic V, Guzma A, "Enhancing Power System Automation Through the Use of Real-Time Ethernet", Power Systems Conference: Advanced Metering, Protection, Control, Communication, and Distributed Resources, 2006.

[8]. Peizhong Yi, Iwayemi A, Chi Zhou, "Developing ZigBee Deployment Guideline Under WiFi Interference for Smart Grid Applications", Smart Grid, IEEE Transactions on (Volume:2 , Issue: 1 ), March 2011

[9]. Andreoni Lopez M.E, Galdeano Mantinan F.J, Molina M.G, "Implementation of

\section{Trang 14}


wireless remote monitoring and control of solar photovoltaic (PV) system" Transmission and Distribution: Latin America Conference and Exposition (T\&DLA), 2012 Sixth IEEE/PES
[10].Rashidi Y, Moallem M, Vojdani S, "Wireless Zigbee system for performance monitoring of photovoltaic panels" Photovoltaic Specialists Conference (PVSC), 2011 37th IEEE 